\title{
The role of women in youth health status- diet and exercise
}

\author{
Adeniji, B. A. ${ }^{8}$
}

\section{Abstract}

Youths of today are leaders of tomorrow. Youth is the time of life when a person is young, especially the time before a child becomes an adult. Health is wealth. It is a common say that a healthy nation is a wealthy nation and since the women in the society stay more at home with the youths, they have important roles to play in taking care of them in terms of their diet and exercise. Youths in the society today are more obese than the adults; this is because they spend less time doing any form of physical activity when compared with the adults who spend more time on physical activities than the youths. It is important in the society to educate our youths on their health, how to improve their diets and encourage physical activities in our homes. This paper examined the roles of women in youth health status - Diet and Exercise. The paper recommended that women and the 3 tiers of government ( that is, local, state/regional, and federal government) should take adequate care of the youths in their homes and the society by providing good diet and allowing them to exercise regularly to keep the body healthy.

Keywords: $\quad$ youth health status, diet, exercise, physical education

\section{Introduction}

Youth is the time of life when a person is young; this is the time before a child becomes an adult. The youths in the society or a nation can be categorized into people that are out of school, differently-abled or physically challenged, school going, rural, urban, unemployed and street youths who are economically and culturally disadvantaged (Fagbola, 20004). Youths undergo changes, including physical, social, cognitive and emotional development. All these need to be taken care of by parents especially mothers in the homes.

According to Women's Sports Foundation (2005), failure to address the development of regular exercise behaviours and good nutrition at an early age has major health and economic consequences. Youths of today are leaders of tomorrow, so there is the need to take adequate care of them in the society in terms of their health - diet and exercise.

This paper discussed the roles of women in youth health status - diet and effects of exercise on their health.

\section{Health and diet}

Health is wealth and good health is a way of life. The first wealth of an individual is health. Health was defined by Williams (1925) as the quality of life that renders the individual fit to live most and serve best. The World Health Organisation (WHO) (1947) gave a comprehensive definition of health as a complete physical, mental, social and emotional well-being of individual

${ }^{8}$ Adeniji, B. A. Dr. (Mrs) lectures at the Physical and Health Education Department, Federal College of Education, Osiele, Abeokuta. E-mail:bolaadeniji1454@yahoo.com 
and not merely the absence of disease or infirmity. Each of these definitions of health reflects a state of being essential to a full and productive life. And in order to have this state of being, certain health practices are essential, unless a balance or steady state may be disrupted and there may be ill-health. Therefore, in order to ensure that proper health habits are established early in life. Health Education is very essential in each community, in our homes and in the country at large.

Diet is food that a person normally eats everyday. There is the balance diet and unbalance diet. A balance diet is one that derives at least $50 \%$ of its energy from carbohydrate containing foods, less than $30 \%$ from fats and 12 to $15 \%$ from protein. This means that balancing ones diet ensures that the body gets what it needs to keep it healthy. Not eating too much fat and having enough fruits, will help one to balance what one eats. The five groups of food needed for a balanced diet are carbohydrates ( bread, cereals, potatoes, pasta, rice and noodles), dairy products (milk, cheese, and yoghurt), fruits and vegetables ( fresh, canned and frozen) and protein (meat, fish, chicken, eggs, nuts, soya mince, beans and so on).

A healthy diet, exercise and mental relaxation can help to keep our youths and adults in the society in good health. It also helps to fight illness and reduce the risk of medical conditions including heart disease and some cancers. The health status of youths in the society may be determined by the wealth of individual. The type of food we eat depends on lots of things like taste, culture, religion, advertising, social pressures and income of the individuals. This means that poverty and inequality are part of the factors that can determine the health of the individual in the society.

Youths in the society today are more obese than the adults; this is because they spend less time doing any form of physical activity when compared with the adults who spend more time on physical activities than the youths. It is important in the society to educate our youths on their health, how to improve their diets and encourage physical activities in our homes. This will be better carried out by the women in the society, who have great roles to play in the health status of our youths.

Exercise is the physical activity performed to show better adaptability to stress, to be less neuromuscular tensed and less fatigue. There are three types of exercise- aerobic exercise, anaerobic exercise and skill development exercise.

Aerobic exercise is any activity which is rhythmic in nature that uses large muscle groups and can be maintained continuously. It is the type of exercise in which the muscles draw on oxygen in the blood as well as fats and glucose that increase cardiovascular endurance. It helps to overload the heart and lungs and causes them to work harder than at rest. The different types of aerobic exercise are walking, jogging, bicycling, swimming, aerobic dancing, racket sports (tennis, squash, table tennis, badminton) rowing, ice or roller skating, cross-country, exercises on aerobic equipment such as treadmill and bicycle ergometer (Body trends. Com.,2004).

Anaerobic Exercise involves intense or explosive Sports of strenuous activity that leave one gasping for breath. This type of exercise can only be done for a minute or two at a time, because it depends on limited store of glycogen sugar stored in the muscles that is rapidly depleted, remitting in intense muscle fatigue. 
Skill development exercise includes flexibility balance and coordination. Exercise helps to improve the health of individual. Inactivity courses so many diseases. Therefore the individual needs to involve himself in physical exercises in order to be fit.

Udo (1982) gave the reports of Kraus and Raab (1961) on the role of inactivity as a cause of disease as follows:

(i) that the coronary heart disease is twice as frequent in sedentary as in the Active people.

(ii) a number of internal and surgical condition such as diabetes and duodenal ulcer are most frequent in sedentary than in the active.

(iii) people experience low back pain because they lack adequate physical activity.

(iv) emotional difficulties are got due to lack of physical fitness.

(v) persons that are physically active exhibit better adaptability to stress, low neuromuscular tension and less fatigability.

(vi) physically active people age late, they also do not tend towards absolute and relative overweight, have lower blood pressure, and they are stronger and more flexible. They also have greater breathing capacity and lower pulse rate Udo (1982).

In order to be physically fit, are needs to take part in aerobic exercises which will help to develop the components of physical fitness such as cardiovascular endurance, flexibility, power, body composition, speed, reaction time, agility, balance and coordination. Exercises should be an integral part of individual's life especially the youths, in order to contribute to healthy way of living in general and physical fitness level in particular. There is no age limit to participating in physical fitness program but this must be individually designed to fit individuals need.

\section{Exercise and youth's health}

Every youth needs exercise which is a sound and largely risk-free investment in their present and future health. According to Ganley and Sherman (2000), Physicians who care for young patients should take an active role in helping them choose and maintain activities appropriate to their age, physical condition, of development and interests. They postulated that ignoring health promotion in young people may reflect two believes (i) that through inactivity is wide spread in adults, children are naturally and spontaneously active, and (ii) that the health risks associated with a sedentary lifestyle such as diabetes and heart disease are far more pressing in adults Di Mubite (1993) stated that fewer than half of U.S. children engage in activity sufficient for cardiovascular benefit and long term health promotion. Overweight children are at increased risk of many health problems, including hypertension, hyperlipidema, type 2 diabetes, growth hormone dysregulation, and respiratory and orthopedic problems (Bar Or, Foreyt, Bouchard et al (1998).

A sedentary left style in young people can have negative health consequence both now and late in life. According to Bar, Or and Baranowski (1994), increasing physical activity while restricting calorie in take has been documented as an effective weight loss strategy. Exercise may lower Osteoporosis risk by increasing bone mineral density. Bradney, Pearce, Navghton, et al (1998) studied 40 pre pubertal boys (mean age, 10 - 14 years), half of whom participated in 30 minutes of weight burning exercise three times a week for 32 weeks land found that the increase 
in lumbar, spine, leg, and total body bone mineral density was twice as great in the exercise group as in control. Bass, Pearce, Bradney, et al (1998) studied 45 pre pubertal female gymnasts (mean age, $10-4$ years) 36 retired gymnasts (mean age, 25 years) and 50 matched controls and found significantly greater bone mineral density in the young and retired gymnasts. The researcher observed that bone density did not diminish during retirement, despite the lower frequency and intensity of exercise. They concluded that exercise before puberty may reduce fracture risk after menopause.

Exercise patterns continue into adulthood. In a study conducted by Trudeau, Laurencelle, Tremblay et al (1999), 174 men and women who had five Physical Education (P.E) sessions per week in the 6 years of elementary school in early1970s were compared with a control group of 720 who had less frequent Physical Education (P.E). When it was surveyed in the mid 1990s, women, but unto men, in the high frequency P.E group reported more frequent physical activity than controls. Men who had more frequent P.E as children were significantly less likely to smoke than controls (11.3\% Vs 30.8\%). Taylor, Blair, Cummings, et al (1999) suggested that childhood exercise, if promoted unwisely, can impede adult physical activity. Exercise is good for all children but every activity is not suitable for every child. The demands of the Sport or exercise activity are to be matched to the developmental maturity of the child.

\section{Principles of aerobic exercise}

In selecting types or modes of aerobic exercise, care must be taken so that there will not be any injury. One should consider the goals, physical condition and injury/illness history. It is however better to alternate between and among several appropriate exercises in order to reduce the chances of overuse injuries, or impose a more balance conditioning stimulus and enhance enjoyment. When you make your mind on taking part in aerobic exercises or keeping fit try to make sure you are performing under an exercise physiologist/trainer in order to obtain quality technique.

In planning fitness programme, there is need to have a complete medical examination, especially for people who are 30 years and above. You need to recondition yourself before commencing on a regular exercise programme, by this you need to warm-up in order to avoid injury. The exercise programme should be worked out by a competent exercise physiologist or trainer/physical education specialist. This is to ensure for a balanced exercise programme which will improve the condition of your lungs cardiovascular system, muscular system and total fitness of the body. Exercise programme should be focused on the major weakness areas of the body such as the hands, arms, shoulder, and upper front muscle and abdominal muscles.

Your goals, schedule and physical condition will determine how long you perform aerobic exercise, 10 to 60 minutes is an acceptable range of time. If your goal is body fat loss, and you are in good condition, then you need to exercise for a longer period, at least 30 minutes, it maybe between 40 to 60 minutes. When starting an exercise, you start from low to moderate intensity, repetitions, or duration of each aerobic exercise. You exercise 3 to 5 times per week. If fat loss is your goal for exercising try to exercise 6 to 7 times in a week that is you exercise nearly every day. Try to gradually increase the duration, intensity and frequency of your exercises. If your goal is to lead a balance life style and enhance your health and well being, you are to perform aerobic exercise regularly even if the intensity is low or the duration is short. For good health 
and well-being enhancement, one needs to get some frequent aerobic activity period, try to enjoy it and take it easy so that one will want to keep it up.

\section{Health benefits of exercises}

Regular physical activity provides so many health benefits. It reduces the risk of dying of coronary heart disease and decreases the risk of stroke, colon cancer, and diabetes and high blood pressure joints.

It helps to relief the pain of arthritis and reduces symptoms of anxiety and depression.

Physical activity improves muscle tone, helps the body to respond to the demands of living and preserves a more desirable appearance. This means that regular physical activity helps in the preservation of the physical characteristics of youth and delay of the on set of the stigmata of ageing. Involvement in regular physical activity conditions, the body and keeps the individual in peak form to be able to combat emergencies of daily loving more effectively.

\section{Roles of women in the youth health status}

Women start their roles as parents right from the time they are looking forward to rearing children by praying hard for the fruit of the womb. When the baby is till in the womb the woman needs to exercise until she delivers the baby. The woman stays more at home more than the Males and so needs to monitor

the activities of the children. Women should get themselves involve in the type of physical exercises their children take part in. They need to relate well with the coaches, teachers physicians, health educators and those who are involve in the developmental stages of the children.

Youths are very restless and they need to be guided so that they will not strain away from having good health. Youth restiveness according to Nwalo (2004) refers to the radical actions and reactions of the youth often in reaction to environmental, policy and other issues perceived to run contrary to their interest. In our society, youth restiveness is generally regarded as a negative concept because of its disruptive and destructive tendencies. Women in the society should try and make sure that they allow the youths to take part in physical exercises which can help to occupy their minds.

Youths are to be well fed, that is they should be given a well balanced diet which will make them healthy, and they are our greater tomorrows. Women should care more about the youths than themselves.

\section{Summary, conclusion and recommendations}

Health is wealth. A healthy nation is a wealthy nation. The youths in the society are the leaders of tomorrow. A healthy diet, exercise and mental relaxation can help to keep our youths and adults in the society in good health. Women in the society should try as much as possible to provide balanced diet for their children.

The following recommendations were made:

That exercises should be an integral part of individual's life in order to contribute to healthy way of living in general and the physical fitness level in particular. 
That health and fitness of the individual should be improved and maintained by participating in regular physical activity programmes such as jogging which is a type of aerobic exercise. The duration of physical activities or exercises should be long enough, say 10 to 60 minutes, depending on the intensity and it should be specific in terms of individual's level of health in order to obtain the desired results.

In order to have a wide spread of opportunities to encourage our youths or individuals in the society to participate in physical activities, there is a great need for government agencies, private individuals and organizations to organize fitness clinics and programmes in which men and women, young and old people in the society can participate.

In conducting exercise programmes that are aimed at influencing the health of individual and physical fitness level, efforts should be made to control other variables that may influence the results. Some of the extraneous factors are the dietary habits and extra-curricular activities of the participants. Exercises should be performed at least 3 times a week.

Women organization should beset $u$ to promote the prevention of obesity through healthy life style practices including physical activity, healthy eating and positive self-esteem.

Women should try and encourage youths to include in their daily eating pattern; at least 3 serving of low fat milk and milk products as a source of calcium which is good for bone health, at least five serving of fruits and vegetables per day; two to three servings of meat or alternates a day and five or more servings of grain products depending on energy requirements.

Youths should be involved in educating other youths on good health habits and effects of exercises on their health.

The three tiers of government (that is, local, state/regional, and federal government) should provide enough facilities for recreation of the youths in other to reduce the rate of their restiveness, so that they will be gainfully engaged.

Women should spend more time with the youths, in advising them on how they can make use of their talents and be useful to the society.

The government and partners in health, education and sport and leisure are to work hand in hand to improve the health of the nation. There is the need to improve diet, encourage physical activity, educate the public and health professionals, teachers; youth workers and parents about the needs and requirements of healthy living should be a priority in our Nation.

\section{References}

Bar-Or O, Baranowski T.A. al (1998). Physical activity, adiposity, and obesity among adolescents. Pediatr Ex Sci 6:348 - 360.

Bar-Or O, Foreyt J, Bouchard C, et al (1998). Physical activity, genetic, and nutritional considerations in childhood weight management. Med. Sci Sport Exerc. 30 (1): 2 - 10.

Bass S, Pearce G, Bradney M, et al (1998). Exercise before puberty may confer residual benefits in bone density in adulthood: studies in active prepubertal and retired female gymnasts. J. Bone Miner Res 13(3): 500 - 507.

Body Trends Com. (2004). Basic Aerobic Exercise Principles for Fitness http///WWW:body trends com 
Bradney M. Pearce G, Naughton G, et al (1998). Moderate Exercise during growth in prepubertal boys: changes in bone mass, size, volumetric density and bone strength: a controlled prospective study. J. Bone Miner Res 13(12): 1814-1821.

Di Nubile, NAA (1993). Youth Fitness: Problems and Solutions. Prev. Med. 22 (4); 589 - 594

Fagbola, B.O. (2004) The role of Sports, Physical Education and Libraries in combating Delinquent Behaviour in Youths Education Today 11(1) 38 - 43.

Ganley Theodore, MD and Sherman, (2000). Exercise and Children's Health. The Physician and Sports medicine 28 (2) February.

Kraus, H. and Raab, W. (1961) Hypokinetic Disease Spring Field: Charles C. Thomas Publishers.

Nwalo, K.I.. (2004). The School Media Resource Centre in Nigeria: A Panacea for Youth Restlessness Education Today 11(1).

Taylor WC, Blair SN, Cummings SS, et al (1999). Childhood and adolescent physical activity patterns and adult physical activity. Med. Sci. sports Exerc. 31 (1):118-123.

Trudeau F, Laurencelle L, Tremblay J, et al (1999). Daily Primary life. Med. Sci. Sports Exerc. 31(1) : $111-117$.

Udoh,C.O. (1982). Role of Exercise in Promotion of Health In Amusa and Udoh(ed) Dynamics of Physical Fitness $34-36$. 